https://helda.helsinki.fi

\title{
Eucapnic voluntary hyperventilation test decreases exhaled nitric oxide level in children
}

\section{Burman, Janne}

2021-01

Burman , J , Malmberg , P , Elenius , V , Lukkarinen, H, Kuusela , T, Mäkelä , M , Remes , S \& Jartti , T 2021, ' Eucapnic voluntary hyperventilation test decreases exhaled nitric oxide level in children ' , Clinical Physiology and Functional Imaging , vol. 41 , no. 1, pp. 1-3 . https://doi.org/10.1111/cpf.1

http://hdl.handle.net/10138/335708

https://doi.org/10.1111/cpf.12673

acceptedVersion

Downloaded from Helda, University of Helsinki institutional repository.

This is an electronic reprint of the original article.

This reprint may differ from the original in pagination and typographic detail.

Please cite the original version. 
1 (Information page, manuscript p 2- )

2 Eucapnic voluntary hyperventilation test decreases exhaled nitric oxide level in

3 children

4 Janne Burman ${ }^{1}$, MD; Pekka Malmberg ${ }^{1}$, MD; Varpu Elenius ${ }^{2}$, MD; Heikki Lukkarinen ${ }^{2}$, MD; Tom

5 Kuusela ${ }^{3}, \mathrm{PhD} ;$ Mika Mäkelä ${ }^{1}, \mathrm{MD}$; Sami Remes ${ }^{3}$, MD; Tuomas Jartti ${ }^{2,4}$, MD

$6 \quad{ }^{1}$ Skin and Allergy Hospital, Helsinki University Hospital and University of Helsinki, Finland

$7 \quad{ }^{2}$ Department of Paediatrics and Adolescent Medicine, Turku University Hospital and University of

8 Turku, Finland

$9{ }^{3}$ Department of Paediatrics, Kuopio University Hospital, Finland

$10{ }^{3}$ Department of Physics and Astronomy, University of Turku, Finland

$11{ }^{4}$ Department of Paediatrics, Oulu University Hospital and University of Oulu, Finland

\section{Correspondence details}

13 Janne Burman

14 E-mail: janne.burman@fimnet.fi

15 Address: Department of Allergology,

$16 \quad$ Skin and Allergy Hospital

17 P.O. Box 160, FIN 00029 HUS

18 Phone: +358505498536

19 Keywords: eucapnic voluntary hyperventilation test, indirect bronchial challenge test, FeNO,

20 exhaled nitric oxide, asthma

21 Conflict of interest: None declared. 
22 Acknowledgments of funding: The sponsor of the study had no role in the analysis, study design or

23 data collection. The corresponding author had the final responsibility for the decision to submit for 24 publication.

25 Abstract: 245 words

26 Word count: 1,301 words

27 Number of tables and figures: 1 table

28 Number of references: 5

29 Abbreviations:

30 EVH: Eucapnic voluntary hyperventilation test

31 FeNO: Exhaled nitric oxide

32 FEV1: Forced expiratory volume in 1 second

33 


\section{Background}

Exhaled nitric oxide (FeNO) measurements and eucapnic voluntary hyperventilation (EVH) tests have been used as diagnostic tools for asthma. Data on the impact of hyperventilation on the level of FeNO are limited.

\section{Aim}

We aimed to evaluate whether EVH tests affect the level of FeNO in children aged 10-16 years.

\section{Methods}

A total of 234 children aged 10-16 years had a 6 min EVH test performed. In total, FeNO values for 153 of 234 children were measured before the test and within 15 minutes after the test. According to a baseline FeNO level of 20 ppb, children were divided into two groups: those with low values ( FeNO $<20 \mathrm{ppb})$ and those with high values ( $\mathrm{FeNO} \geq 20 \mathrm{ppb})$.

\section{Results}

The median age of the children was 13.4 years (interquartile range $12.3-15.3$ years); $58 \%$ were boys and $42 \%$ were girls. Of these children, $51 \%$ were sensitized to aeroallergens. In 101 of 153 children (66\%), the FeNO values decreased after the EVH test. In children with low and high baseline levels, the median level of FeNO decreased after the EVH test: 10.5 ppb before vs 9.5 ppb after $(p<.011)$, and $31.0 \mathrm{ppb}$ before vs $28.0 \mathrm{ppb}$ after $(p<.011)$, respectively. The decrease in

1 FeNO after EVH test was not associated with induced bronchoconstriction expressed as a change in $2 \operatorname{FEV} 1\left(\mathrm{R}_{\mathrm{s}}=.19\right)$.

\section{Conclusions}

54 The EVH test decreases FeNO levels. Therefore, FeNO should be measured before an EVH test is performed. 
57 The exhaled nitric oxide (FeNO) measurement is used to assess asthma and asthma-control worldwide. The level of FeNO predicts the response to inhaled corticosteroids in asthma patients (Dweik RA et al., 2011). Monitoring asthma with FeNO reduces exacerbations among children but

60

61 does not impact day-to-day symptoms (Petsky HL et al., 2016). Studies among children have shown that the level of FeNO decreased after performing the mannitol dry powder challenge and exercise test (Barben J et al., 2013; Petsy HL et al., 2013). The American Thoracic Society recommends that FeNO be performed before a bronchial challenge test (Dweik RA et al., 2011). So far, the effect of a eucapnic voluntary hyperventilation (EVH) test on FeNO among children has not been studied.

We examined whether EVH tests affect the FeNO level in children aged 10-16 years. We hypothesized that an EVH test would decrease FeNO level.

In the beginning, 234 children (134 patients and 100 controls) aged 10-16 years participated in the study at the paediatrics departments of the university hospitals of Turku and Kuopio, Finland and performed the EVH test between years 2013-2016. The inclusion criteria for the patients in the study were exercise-induced dyspnea symptoms and a referral from a primary or secondary health care provider. The exclusion criteria were physical inactivity, severe comorbidity, chronic autoimmune disease or difficult-to-treat asthma. The Ethics Committee of the Hospital District of Southwest Finland approved the study, and written consent was collected from every patient and their parents upon entrance to the study.

SPSS version 22 (IBM Corp, Armonk, NY, USA) was used for the statistical analysis. The FeNO data were not normally distributed (Shapiro-Wilks test, $p<.001$ ). The data has presented as median and interquartile range. For continuous data, the Wilcoxon Signed-Rank test and the Mann-Whitney U test were used. For categorical data, the chi-square test and Fisher's exact test (when counts $<5$ ) were used. The Spearman correlation test was used for the correlation analysis. In the subgroup 
analysis, Bonferroni correction was performed to control for type I error. Statistical significance was established at $p<.05$.

The EVH test was conducted according to European Respiratory Society guidelines for the indirect bronchial challenge test (Hallstrand TS et al., 2018). The spirometry was performed using Jaeger SentrySuite-equipment (version 2.19) before the EVH test and 1, 5 and $10 \mathrm{~min}$ after the test.Target minute ventilation was defined as 30 times the patient's baseline forced expiratory volume in 1 second (FEV1), corresponding to $85 \%$ of maximal voluntary ventilation (MVV; Hallstrand TS et al., 2018). The feasibility of the EVH test was assessed by the ability of the children to achieve $70 \%$ of the target ventilation volume (Hallstrand TS et al., 2018).

FeNO level was measured before and within 15 minutes after the EVH test. The data were analysed using NIOX Vero (Aerocrine, Solna, Sweden) according to international guidelines with a flow rate of $50 \mathrm{ml} / \mathrm{s}$ (Dweik RA et al., 2011). Phadiatop tests were performed for 138 of 153 children.

Sensitization was defined if $\operatorname{sIgE} \geq 0.35 \mathrm{kU} / \mathrm{l}$ occurred for at least one of the tested allergens.

Of all children, the FeNO levels of 55 out of 100 controls and 98 out of 134 patients were measured during the visit. Those 153 children were included in the analysis. For 81 children, the FeNO testing was not available due to technical problems.

The median age of the children was 13.4 years (interquartile range $12.3-15.3$ years); $58 \%$ were boys and 51\% were sensitized to aeroallergens. Based on the baseline FeNO results, the children were divided into two groups, with either a low $(<20 \mathrm{ppb}, n=112)$ or high $(>20 \mathrm{ppb}, n=41)$ level of FeNO. The sensitization to aeroallergens was more frequent among children with high FeNO ( $80 \%$ vs $41 \%, p<.001)$. There were no significant differences between groups in terms of median age (13.4 vs 14.1 years, $p=.060)$, prevalence of asthma (19\% vs $23 \%, p=.72)$, allergic rhinitis ( $39 \%$ vs $54 \%, p=.10)$ or atopic eczema $(24 \%$ vs $28 \%, p=.61)$. In both groups, the majority of 
children were boys, and both groups performed well on the EVH test; a minimum of $70 \%$ of target ventilation was reached by 150 of 153 children.

Among all children, the median level of FeNO decreased significantly after EVH (13.0 ppb before vs $11.0 \mathrm{ppb}$ after, $p<.011)$. FeNO decreased in children with low $(10.5 \mathrm{ppb}$ before vs $9.5 \mathrm{ppb}$ after, $p<.011)$ and high (31.0 ppb before vs $28.0 \mathrm{ppb}$ after, $p<.011)$ levels compared to the baseline (Table 1). In children with high FeNO, the absolute change in FeNO was greater compared to children with low FeNO (-3 ppb vs -1 ppb, $p=.011)$. However, expressed as a percentage change comparing baseline FeNO, the change was similar among children with high and low FeNO ($11.1 \%$ vs $-12.0 \%, p=.45$ ). There were no significant differences between boys and girls in the results $(-1 \mathrm{ppb}$ vs $-2 \mathrm{ppb}, p=.63)$.

All other subgroups had significant decreases of FeNO after EVH except for children with a minimum 10\% fall of FEV1 after EVH (Table 1). The decrease in FeNO after EVH was not correlated with age $\left(\mathrm{r}_{\mathrm{s}}=-.14\right)$, fall of forced expiratory volume in 1 second $(\mathrm{FEV} 1)$ after $\mathrm{EVH}\left(\mathrm{r}_{\mathrm{s}}=\right.$ $.19)$ or achieved minute ventilation during the EVH test $\left(\mathrm{r}_{\mathrm{s}}=.02\right)$.

The decrease in FeNO was seldom at a clinically relevant level. Fifteen children had a baseline FeNO > 35 ppb, predicting good responsiveness to corticosteroids (Dweik RA et al., 2011), whereas after the EVH test, 9 children had FeNO > 35 ppb $(p=.20)$. Accordingly, the FeNO cutoff value of $<20 \mathrm{ppb}$ predicting a less favourable response to corticosteroids (Dweik RA et al., 2011) was observed in 112 children before the EVH test vs 115 children after the test $(p=.73)$. A minimum decrease of 10 ppb of FeNO was observed for 4 of 153 (2.6\%) children.

The American Thoracic Society recommends performing FeNO before bronchial challenges (Dweik RA et al., 2011). In previous studies, the level of FeNO decreased after the exercise test and mannitol challenge (Barben J et al., 2013; Petsy HL et al., 2013). Our findings with the EVH test 
are in line with these earlier observations. To our knowledge, this was the first time the effect of the

127

128

129

130

131

\section{CONFLICTS OF INTEREST}

146 The authors have no conflict of interest to declare. 


\section{REFERENCES}

148 Barben J, Strippoli MP, Trachsel D, Schiller B, Hammer J, Kuehni CE. Effect of mannitol dry

149 powder challenge on exhaled nitric oxide in children. PloS One (2013); 8(1): e54521

150 Dweik RA, Boggs PB, Erzurum SC, Irvin CG, Leigh MW, Lundberg JO, Olin A-C, Plummer AL,

151 Taylor R. An official ATS clinical practise guideline: Interpretation of exhaled nitric oxide levels

152 (FeNO) for clinical application. Am J Respir Crit Care Med (2011); 184: 602-15.

153 Hallstrand TS, Leuppi JD, Joos G, Hall GL, Carlsen KH, Kaminsky DA et al. ERS technical

154 standard on bronchial challenge testing: Pathophysiology and methodology of indirect airway

155 challenge testing. Eur Respir J (2018); 15:52(5) pii: 1801033.

156 Petsky HL, Kew KM, Chang AB. Exhaled nitric oxide levels to guide treatment for children with

157 asthma (Review). Cochrane Database Syst Rev (2016); 11: CD011439.

158 Petsy HL, Kynaston JA, McElrea M, Turner C. Isles A, Chang AB. Cough and exhaled nitric oxide

159 levels: What happens with exercise? Front Pediatr (2013); 24:30. doi: 10.3389/fped.2013.00030. 
160 TABLE 1. Exhaled nitric oxide (FENO) before and within 15 minutes after a eucapnic voluntary 161 hyperventilation test $(\mathrm{EVH})$

\begin{tabular}{|c|c|c|c|}
\hline Group & $\begin{array}{l}\text { Baseline FeNO } \\
\text { (ppb) }\end{array}$ & $\begin{array}{l}\text { The change of } \\
\text { FENO after } \\
\text { EVH (ppb), }\end{array}$ & $\begin{array}{l}\text { Bonferroni } \\
\text { corrected P- } \\
\text { value }\end{array}$ \\
\hline $\begin{array}{l}\text { All children } \\
N=153\end{array}$ & $13.0(9-20)$ & $-2.0(-4-0)$ & .011 \\
\hline $\begin{array}{l}\text { Patients } \\
n=98\end{array}$ & $13.0(9-23)$ & $-2.0(-4-0)$ & .011 \\
\hline $\begin{array}{l}\text { Controls } \\
n=55\end{array}$ & $12.0(9-18)$ & $-1.0(-3-0)$ & .011 \\
\hline $\begin{array}{l}\text { Children with FeNO } \\
\geq 20 \mathrm{ppb} \\
n=41\end{array}$ & $31.0(24.5-39.5)$ & $-3.0(-8-(-1))$ & .011 \\
\hline $\begin{array}{l}\text { Children with FeNO } \\
<20 \mathrm{ppb} \\
n=112\end{array}$ & $10.5(8-13.5)$ & $-1.0(-2.5-0)$ & .011 \\
\hline $\begin{array}{l}\text { Children with fall in } \\
\text { FEV1 } \geq 10 \% \text { after } \\
\text { EVH } \\
n=16\end{array}$ & $13.0(10.5-28.5)$ & $-2.5(-5-0.5)$ & .242 \\
\hline $\begin{array}{l}\text { Children with fall in } \\
\text { FEV1 <10\% after } \\
\text { EVH } \\
n=137\end{array}$ & $13.0(9-19)$ & $-1.0(-3-0)$ & .011 \\
\hline $\begin{array}{l}\text { Children with doctor } \\
\text { diagnosed atopic } \\
\text { eczema } \\
n=38\end{array}$ & $12.5(9-20)$ & $-2.0(-4-0)$ & .011 \\
\hline $\begin{array}{l}\text { Children without } \\
\text { doctor diagnosed } \\
\text { atopic eczema } \\
n=109\end{array}$ & $12.0(9-19)$ & $-1.0(-3-0)$ & .011 \\
\hline $\begin{array}{l}\text { Children with } \\
\text { sensitization to } \\
\text { aeroallergen \# } \\
n=70\end{array}$ & $12.5(9-29)$ & $-1.0(-4-0)$ & .011 \\
\hline $\begin{array}{l}\text { Children without } \\
\text { sensitization to } \\
\text { aeroallergen } \\
n=68\end{array}$ & $12.0(9-16)$ & $-2.0(-4-0)$ & .011 \\
\hline
\end{tabular}

162 Data represents the medians and the interquartile_range.

163 EVH: eucapnic voluntary hyperventilation test; FeNO: exhaled nitric oxide; FEV1: forced 164 expiratory volume in 1 second. \# defined if $\operatorname{sgE} \geq 0.35 \mathrm{kU} / 1$ any of eight allergens in the Phadiatop. 165 Calculated using a Wilcoxon Signed Rank Test. 